Check for updates

Cite this: RSC Adv., 2017, 7, 33875

Received 3rd May 2017

Accepted 28th June 2017

DOI: $10.1039 / \mathrm{c} 7 \mathrm{ra0} 4973 \mathrm{k}$

rsc.li/rsc-advances

\section{Novel process for producing hierarchical carbide derived carbon monolith and low carbon ferromanganese from high carbon ferromanganese}

\author{
Wei Liu, (iD ab Guolong Liu, ${ }^{\text {ab }}$ Qian Kou ${ }^{\text {ab }}$ and Saijun Xiao *ab
}

In this work, remelted high carbon ferromanganese was chosen as a consumable anode to produce porous carbon monolith and low carbon ferromanganese at the same time by molten salt electrolysis. During potentiostatic electrolysis, the anode fed manganese ions and iron ions into molten salts, with porous carbon left at the anode and ferromanganese deposited on the cathode. The anode residue was characterized by $\mathrm{X}$ ray diffraction, scanning electron microscopy, Raman spectrum and transmission electron microscopy. Results indicated that this type of porous carbon material with a high degree of graphitization has a multimodal pore system consisting of micropores, mesopores and macropores, which is hierarchical carbide derived carbon (CDC). The anode and cathode current efficiencies are estimated to be at least $92 \%$ and $80 \%$, respectively. All results implied that it is feasible to prepare carbide derived carbon monoliths with a hierarchical pore structure and low carbon ferromanganese simultaneously by molten salt electrolysis.

\section{Introduction}

Carbide derived carbon (CDC), as a new type of porous carbon material which shows many unique properties, e.g., controllable pore size distribution, high stability, good electron conductivity and high specific surface area, has been developed as an attractive carbon material for use in electric double-layer capacitors, gas storage and catalyst supports. ${ }^{1-6}$ Nevertheless, this type of porous carbon is limited to be utilized in relatively narrow fields because of its complicated synthesis process and single pore size distribution.

Many methods have been developed to produce CDC efficiently. Commonly, CDC is obtained by chlorination of pure metal carbides at high temperatures with metal atoms removed and CDC left in the precursor. There is a potentially large risk during this production process because of the use of a large amount of chlorine. Thus, more and more attention has been paid to molten salt electrolysis for the preparation of CDC because of its short process, low cost, and environmental friendliness..$^{7-10}$ Actually, in the 1990s, Kroto et al. ${ }^{11-13}$ applied molten salt electrolysis for the formation of nano-structured porous carbon successfully. In recent years, some researchers ${ }^{14-17}$ have also synthesized different kinds of CDC with a great deal of micropores which provide a high specific area via electrolysis of various precursors (e.g., TiC, SiC, WC and VC) in

${ }^{a}$ School of Metallurgy Engineering, Anhui University of Technology, NO.328, Huolishan Street, Yushan District, Maanshan 243000, Anhui, PR China.E-mail: xiaosaijunzj@ yahoo.com

${ }^{b}$ Key Laboratory of Metallurgical Emission Reduction \& Resources Recycling, Anhui University of Technology, Maanshan, Anhui, China, 243000 molten salts, demonstrating the feasibility of this method. Although so many attempts have been made to prepare CDC, the difficulty of producing materials with hierarchical pores (i.e., mixture of micropores, mesopores and macropores) still exists. The presence of micropores and mesopores are needed to provide high capacities, and the existence of macropores make sure that electrolyte ions could enter the inner micropores effectively. In addition, the preparation of the precursors used in the chlorination process requires high-purity carbon and metal powders as raw materials, which also increases the production cost. Therefore, it is necessary to find a type of cheap raw material to prepare low-cost hierarchical porous carbon. High carbon ferroalloy is a type of carbon-saturated ferroalloy obtained by reducing iron oxide ore with a carbonaceous reducing agent, which contains a content of carbon from 6 to $8 \mathrm{wt} \%$. It was found that ${ }^{18,19}$ in addition to a large number of metal carbides, this type of high carbon ferroalloy contains micron-sized metal solid solution phase, which is consistent with the requirements for the raw materials to prepare hierarchical CDC. Moreover, the high carbon ferroalloy will keep an original shape after electrolysis because of its high carbon content. It was reported that ${ }^{20-22} \mathrm{CDC}$ can be fabricated in different textures and shapes such as thin films and monolith which show higher storage capacity than CDC powders. Until now there have been no any reports regarding manufacturing hierarchical porous carbon by electrolysis of high carbon ferroalloy in molten salts.

Manganese, an important industrial material, has been used in many fields such as nonferrous metallurgy, chemical engineering, preparation of electronic materials and alloy steel manufacturing, especially in iron and steel industry which consumes more than $90 \%$ of the produced manganese. ${ }^{23-28}$ Recently, more interests in 
the preparation of manganese were triggered because of their use in high manganese (10-30\%) and high strength automotive steel, also named high-Mn TWIP steel, which can lead to a reduction of the weight and improvement of the safety of cars..$^{28-31}$ However, the manufacturing of this type of steel commercially was still obstructed because of the high cost of the production of manganese. In practice, manganese and its alloys are prepared via electrolysis process of manganese sulfate or manganese chloride, but the low current efficiency and high cell potential increase the energy consumption of this method. In addition, the main raw material for the production of pure manganese, manganese carbonate, is depleting rapidly. Therefore, it is necessary to find a good method or low-cost raw materials to prepare cheap and high-purity manganese or ferromanganese. The decarburization process of HCMnFe has been employed to produce low carbon ferromanganese for a long time. ${ }^{32-36}$ However, there is a large amount of manganese remained in slag during decarburization process, which leads to high energy consumption and low metal yield during refining process. In recent years, Xiao et al. ${ }^{37}$ employed HCMnFe as a raw material and prepared low carbon ferromanganese successfully, demonstrating molten salt electrolysis is a promising and feasible method for the production of low carbon ferromanganese. The mechanism of the anode dissolution was mainly discussed, but no much attention was paid to the anode residue (i.e., carbon) after electrolysis.

Based on the above description, it is obvious that molten salt electrolysis could be utilized to produce CDC and pure ferromanganese, respectively. Notably, it would be a more favorable method if we could prepare hierarchical CDC and pure ferromanganese simultaneously by this method from HCMnFe. Therefore, in this present work, we report the direct preparation process of low carbon ferromanganese and hierarchical CDC monoliths at the same time from $\mathrm{HCMnFe}$ in $\mathrm{NaCl}-\mathrm{KCl}-\mathrm{MnCl}_{2}$ system. The produced hierarchical CDC monoliths were characterized by various methods. The schematic diagram of the whole manufacturing process is presented in Fig. 1.

\section{$\mathbf{a}$}

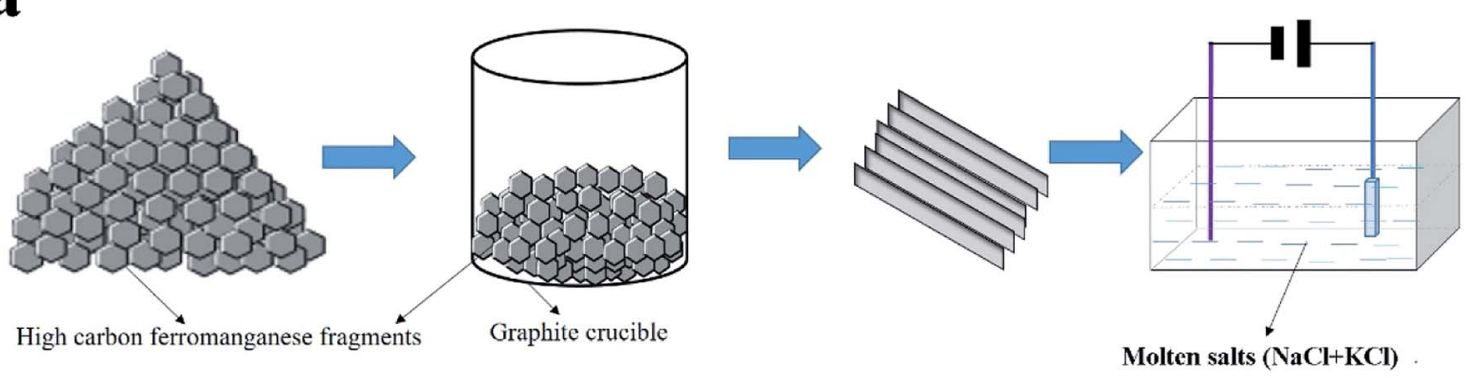

$\begin{array}{llll}\text { a. Material preparation } & \text { b. } \mathrm{HCMnFe} \text { remelting } & \text { c. HCMnFe cutting } & \text { d. Molten salts electrolysis }\end{array}$

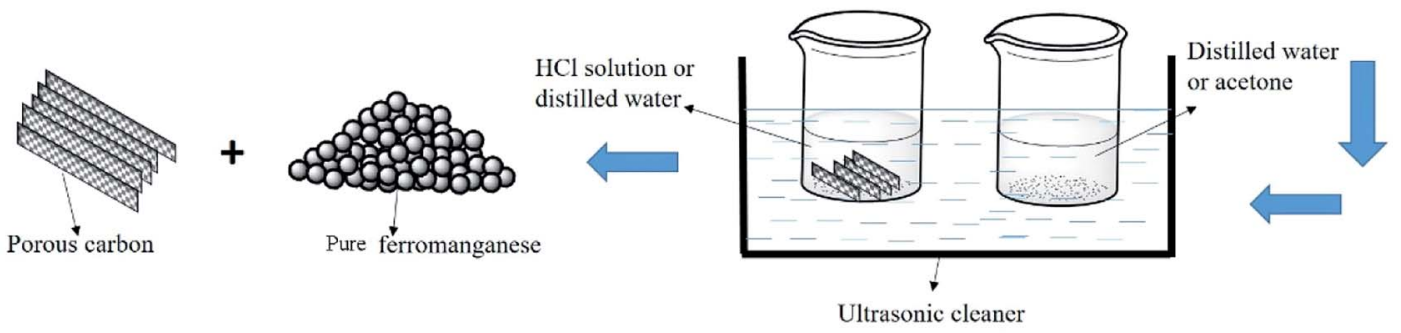

f. Products collection

e. Corrosion treatment, washing and drying

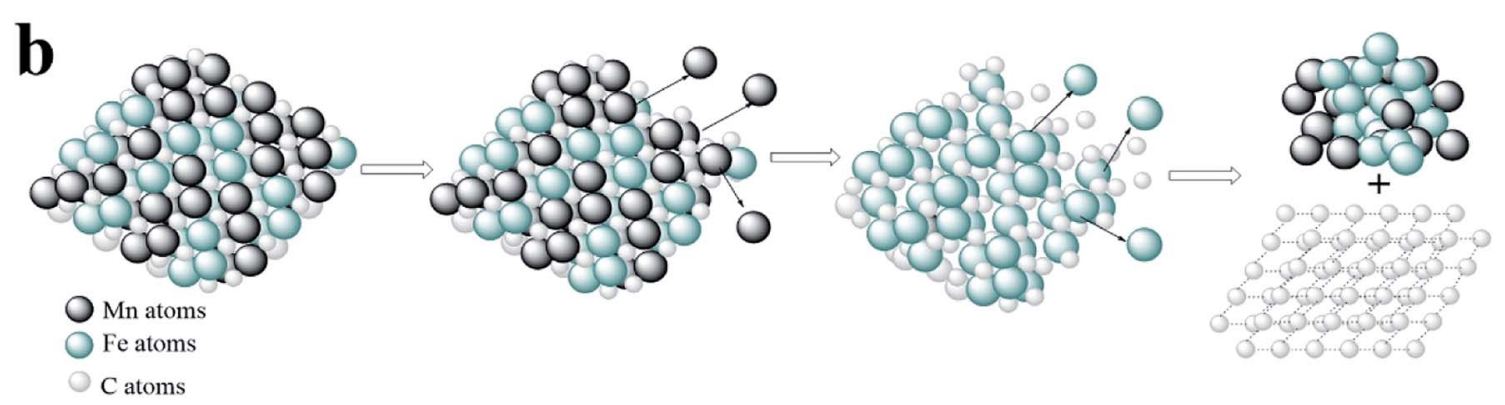

First anode reaction Followed anode reaction Ferromanganese and poroüs carbon

Fig. 1 (a) Schematic illustration of the whole manufacturing process for pure ferromanganese and porous carbon. (b) Schematic diagram of molten salt electrolysis process in (a). 


\section{Experimental}

\subsection{Preparation of the precursor}

As is shown in Fig. 1(a), steps a-c correspond to the preparation procedures of the precursor. The raw material for this work is HCMnFe (75.41 wt\% Mn; 17 wt\% Fe; 6.38 wt\% C). They were put into a graphite crucible positioned in a vacuum tube furnace which provided a sufficient temperature $\left(1350{ }^{\circ} \mathrm{C}\right)$ for the melting of HCMnFe. Ar was supplied continuously during the remelting process until the specimen was taken out. This process has two purposes that are improving the graphitization degree of the precursor and making its composition more uniform.

\subsection{The cell and the electrodes}

All reagents in this experiment were analytical grade, and $\mathrm{NaCl}$ and $\mathrm{KCl}$ melt was pre-dried at a temperature of $200{ }^{\circ} \mathrm{C}$ under vacuum for more than $48 \mathrm{~h}$ to remove surface water. Then an equimolar $\mathrm{NaCl}-\mathrm{KCl}$, used as the supporting electrolyte, and 1 $\mathrm{wt} \% \mathrm{MnCl}_{2}\left(0.48 \mathrm{wt} \% \mathrm{Mn}^{2+}\right)$ added which is to avoid the electrodeposition of alkali metals at the beginning of electrolysis, were mixed homogeneously. Afterwards, the mixed salts were transferred to an alumina crucible, which was held by a graphite supporter connected with a stainless steel bar positioned in a programmable vertical furnace. The furnace provided the required heat to keep a constant temperature during the experiment. A prepared flaky HCMnFe connected with a thin molybdenum wire serving as a current lead was used as the anode, and a tungsten wire with a diameter of $1 \mathrm{~mm}$ shielded with a thin corundum tube was chosen as the cathode which was dipped into electrolyte for about $10 \mathrm{~mm}$. Before being inserted into electrolyte, the two electrodes were polished with fine sand paper and rinsed with ethanol. It was under $\mathrm{Ar}$ atmosphere in the electrolytic cell.

\subsection{Electrolytic reactions}

A constant potential electrolysis $(2.5 \mathrm{~V})$ was conducted with a DC regulated power source. When the as-prepared HCMnFe anode was dipped into the electrolyte, the consumable anode fed manganese ions into the electrolyte, followed by iron ions. All dissolved metal ions were reduced to metal on the cathode. At last, there is only porous carbon left in the anode. The microscopic schematic of molten salt electrolysis process was clearly shown in Fig. 1(b).

\subsection{Collection and characterization of the products}

After electrolysis, all electrodes were lifted above the cell, and when the furnace was cooled down to room temperature, the electrolytic products on the cathode and in electrolyte were collected. The cathode products were washed in distilled water in ultrasonic cleaner, then rinsed with acetone and dried in vacuum drying oven. In the same way, the post-electrolysis anode was collected after being washed with distilled water and $1.5 \mathrm{~mol} \mathrm{~L}^{-1}$ $\mathrm{HCl}$ solution, as shown in Fig. 1(a). The obtained cathode products were characterized by X-ray diffraction (XRD) and scanning electron microscopy (SEM). The elemental content analysis of cathode products for computing current efficiency were determined via X-Ray Fluorescence (XRF). The carbon content of the deposits were measured by a C-S analyzer. The left anode was examined by several different techniques: (a) the composition and phase of the specimen was analyzed via XRD; (b) SEM attached with energy disperse spectroscopy (EDS) facility was employed to obtain the morphology and elemental analysis of the products; (c) the crystal structure was characterized by transmission electron microscopy (TEM); (d) Raman spectra was chosen to examine the degree of graphitization; (e) $\mathrm{N}_{2}$ adsorption was used to get some information about the specific surface area, pore size distribution, etc. Prior to an adsorption test, the specimen was pretreated at $200{ }^{\circ} \mathrm{C}$ for $6 \mathrm{~h}$ under vacuum. The surface area was calculated by the BET equation and the pore size distribution was calculated by the NLDFT method.

\section{Results and discussion}

\subsection{Electrolysis}

Potentiostatic electrolysis $(2.5 \mathrm{~V})$ was carried out for $12 \mathrm{~h}$ in an electrolyte of $\mathrm{NaCl}-\mathrm{KCl}-\mathrm{MnCl}_{2}$, with $\mathrm{HCMnFe}$ and tungsten as the anode and cathode, respectively. The pictures of the anode and cathode before and after electrolytic reactions are shown in Fig. 2. It can be seen clearly that before electrolysis the HCMnFe anode has a smooth and metallic appearance. After electrolysis, the anode surface becomes black and rough, but its shape is almost maintained. In addition, the weight of the anode after electrolysis is decreased greatly than that of before electrolysis. All evidences implies that the anode was consumed during the electrolysis in the $\mathrm{NaCl}-\mathrm{KCl}$ melt. At the same time, a large number of brown products was electrodeposited on the cathode, as shown in Fig. 2. A preliminary prediction of the products should be ferromanganese.

The XRD patterns of the as-prepared anode and postelectrolysis anode are shown in Fig. 3(a) and (b), respectively. Fig. 3(a) shows that the raw material for electrolysis is composed of $\mathrm{Mn}_{7} \mathrm{C}_{3}, \mathrm{Mn}_{23} \mathrm{C}_{6}$, and $\mathrm{Fe}_{3} \mathrm{C}$. After electrolysis, there is only graphite left in the anode residue, indicating that all metals were removed from the anode. The morphology evolution from HCMnFe to graphite was analyzed by SEM given in Fig. 3(c) and

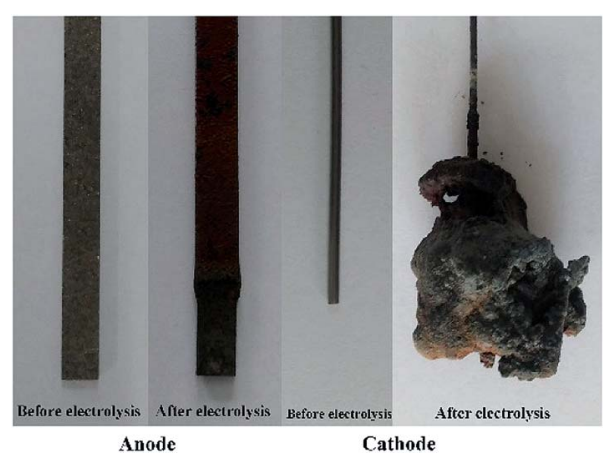

Fig. 2 The photos of electrodes before and after electrolysis in $\mathrm{NaCl}-$ $\mathrm{KCl}-\mathrm{MnCl}_{2}$ for $12 \mathrm{~h}$ at the temperature of $710^{\circ} \mathrm{C}$. 

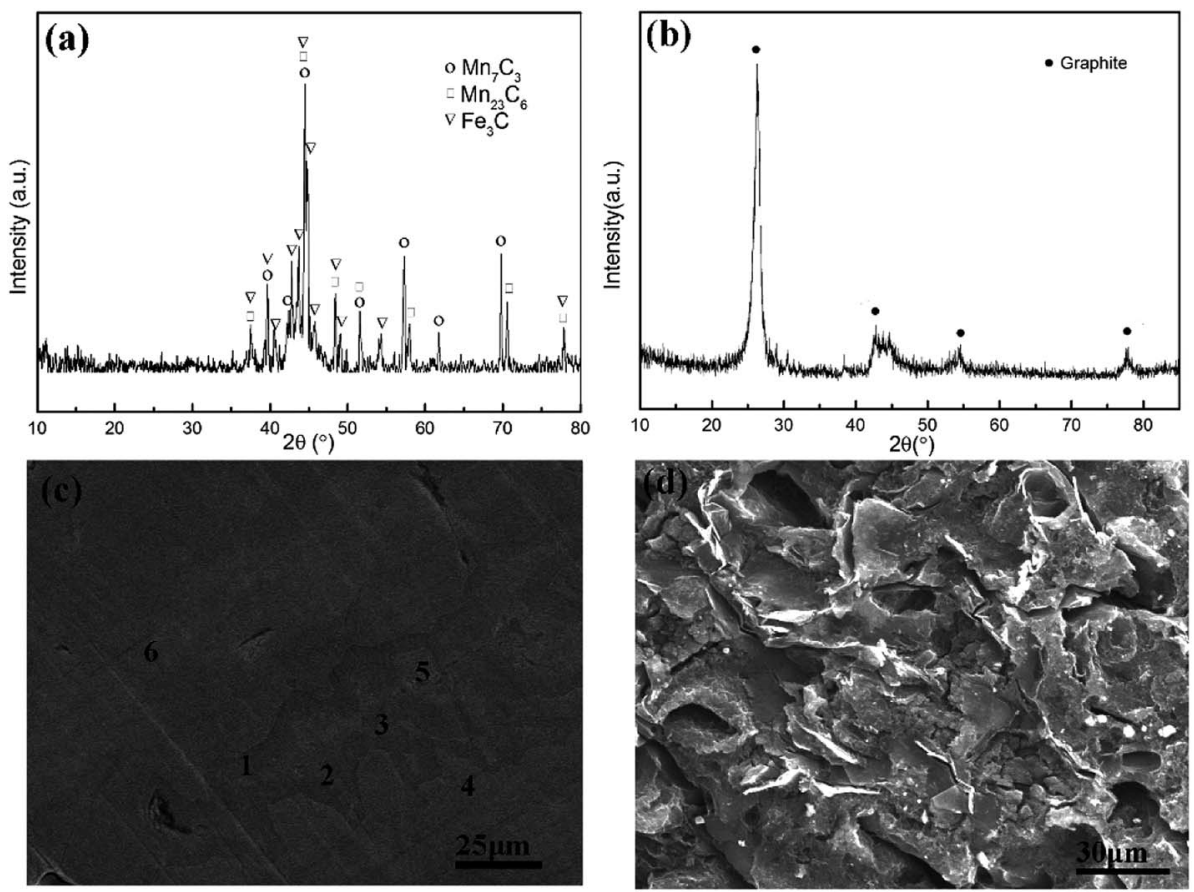

Fig. 3 XRD pattern of anode before electrolysis (a) and after electrolysis (b) SEM image of anode before electrolysis (c) and SEM image of anode after electrolysis (d).

(d). It can be observed that two phases exist in the original anode, which are dark gray and bright gray phases. From the EDS analysis given in Table 1, it is found that the dark gray and bright gray phases are distinguished by the content of carbon. The dark gray phase (about $10 \mathrm{wt} \%$ ) contains more carbon than that in the bright grey phase (about $8 \mathrm{wt} \%$ ). Notably, whether in the dark gray phase or the bright phase, the carbon content of them is more than $6.38 \mathrm{wt} \%$, which is attributed to the remelting process of the starting HCMnFe in graphite crucible. The microstructure of anode residue, shown in Fig. 3(d), indicates that the anode reaction resulted in the presence of different kinds of pores in the anode. Actually, the left anode carbon material not only contains hierarchical pore system but also keeps its original shape of monolith. It is known as carbide derived carbon (CDC) and the corresponding characterization and the synthesis mechanism will be discussed in detail in the next part.

\subsection{Characterization of anode products}

The CDC monolith was characterized via XRD and Raman spectroscopy, respectively. It was mentioned in Fig. 3(b) that the

Table 1 The content of carbon in different areas in Fig. 3(c)

\begin{tabular}{lc}
\hline Area & Contents of carbon (wt\%) \\
\hline 1 & 10.61 \\
2 & 10.22 \\
3 & 10.05 \\
4 & 8.21 \\
5 & 7.92 \\
6 & 8.13
\end{tabular}

porous carbon monolith is known as graphite. As shown in Fig. 4(a) the XRD pattern in the angel ranging from $10^{\circ}$ to $80^{\circ}$ illustrates that the reflections of this type of porous carbon correspond to the (002) plane at $2 \theta \approx 26^{\circ},(100)$ plane at $2 \theta \approx$ $43^{\circ},(004)$ plane at $2 \theta \approx 54^{\circ}$ and (110) plane at $2 \theta \approx 78^{\circ}$, respectively. The diffraction peak of the 002 crystal surface is due to the parallel stacking of the graphite layer. Based on the position of diffraction peak and Bragg equation that is $d_{002}=\lambda /$ $(2 \sin \theta)$, the value of $(002)$ plane spacing $\left(d_{002}\right)$ was calculated, and the result is $0.337 \mathrm{~nm}$, which is close to theoretical spacing of graphite $(0.335 \mathrm{~nm}){ }^{38}$ The high intensity and narrow width indicates the sample has a good graphite structure. Fig. 4(b) gives the Raman spectra of the produced CDC monolith. The presence of D-band at $1360 \mathrm{~cm}^{-1}$ is attributed to the defect of the crystal lattice, irregular edge arrangement and poor symmetry in graphite layer, which can be seen as a breathing mode with $A_{1 \mathrm{~g}}$ symmetry. ${ }^{39}$ The G-band at $1580 \mathrm{~cm}^{-1}$ is expressed as the structural graphite which is due to the stretching vibration of $\mathrm{C}-\mathrm{C}$ bond in $\mathrm{sp}^{2}$ configuration with $E_{2 \mathrm{~g}}$ symmetry in the crystal lattice. All evidence confirms that the left anode carbon monolith is composed of amorphous and graphite carbon. In addition, the value of $I_{\mathrm{D}} / I_{\mathrm{G}}$ implies this material is of high degree of graphitization which will lead to a considerable increase in the conductivity of the material.

Fig. 5 shows the SEM and TEM images of the CDC monolith. It is observed that the CDC monolith contains micropores, mesopores, and macropores inside. Fig. 5(a) and (b) shows clearly that many macropores are surrounded by mesopores. The macropores and mesopores are formed as a result of the interconnection between the carbon sheets which can be seen clearly in Fig. 5(a) and (b). The presence of them could be 

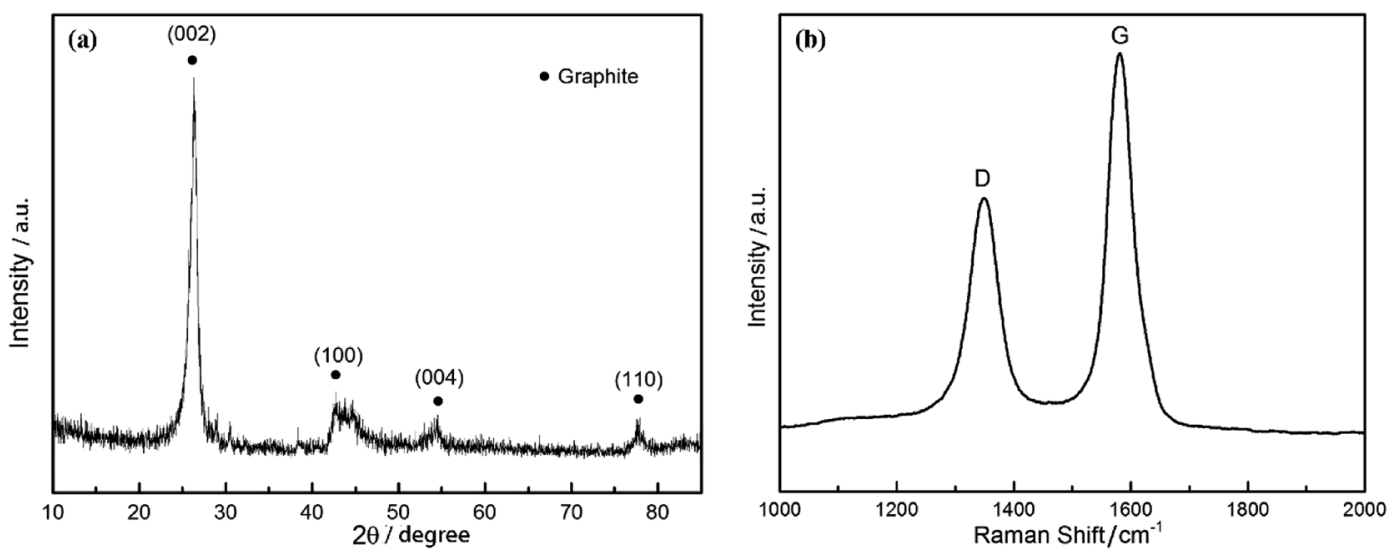

Fig. 4 (a) XRD pattern of the CDC monolith, and (b) Raman spectra of the CDC monolith.
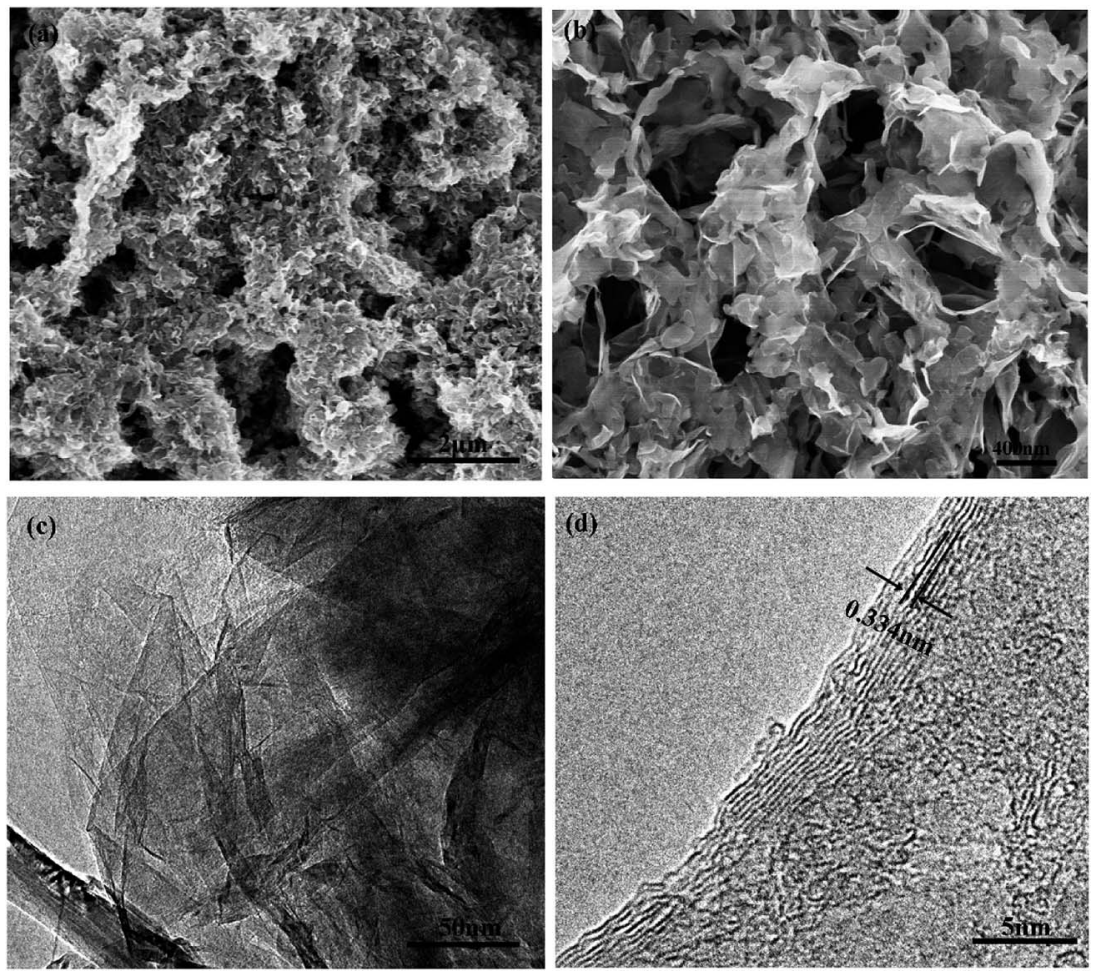

Fig. 5 (a) and (b) SEM images of the CDC monolith with different magnification. (c) and (d) TEM images of the CDC monolith.

favorable for electrolyte entering into the internal pores. TEM images shown in Fig. 5(c) and (d) illustrate that the as-prepared sample contains a microporous structure. The micropores existing in the interconnected carbon sheets are attributed to the demetallization of carbides in HCMnFe. It contains a large amount of carbides (more than 95\%) which ensure the presence of a large number of micropores and small mesopores which could provide high capacity. Graphitic carbon and amorphous carbon were observed from the TEM images at the same time. The value of the lattice spacing is around $0.334 \mathrm{~nm}$ shown in Fig. 5(d), which is in good agreement with the result calculated from the XRD pattern. Therefore, the results of the SEM and TEM images imply that the hierarchical CDC monolith has been successfully prepared by molten salt electrolysis.
In Fig. 6(a), the $\mathrm{N}_{2}$ adsorption-desorption isotherms of the CDC monolith showing a type IV curve with an obvious H3-type hysteresis loop is given. It is observed that there is a large amount of adsorption at the low relative pressure $\left(P / P_{0}<0.01\right)$, demonstrating the CDC monolith has a great deal of micropores. ${ }^{40}$ With the increasing of relative pressure $\left(P / P_{0}\right)$, the adsorbed volume increases, however, the slope of the curve is far lower than that of low relative pressure region for micropores, which is attributed to the volume filling of mesoporosity. ${ }^{41}$ In addition, it is found that there is a high nitrogen uptake in the region of relative pressure ranging from 0.9 to 1.0, which is due to the existence of macropores. ${ }^{42}$ All results are consistent with SEM and TEM results. Fig. 6(b) shows the pore size distribution analyzed via the NLDFT method. It is observed 

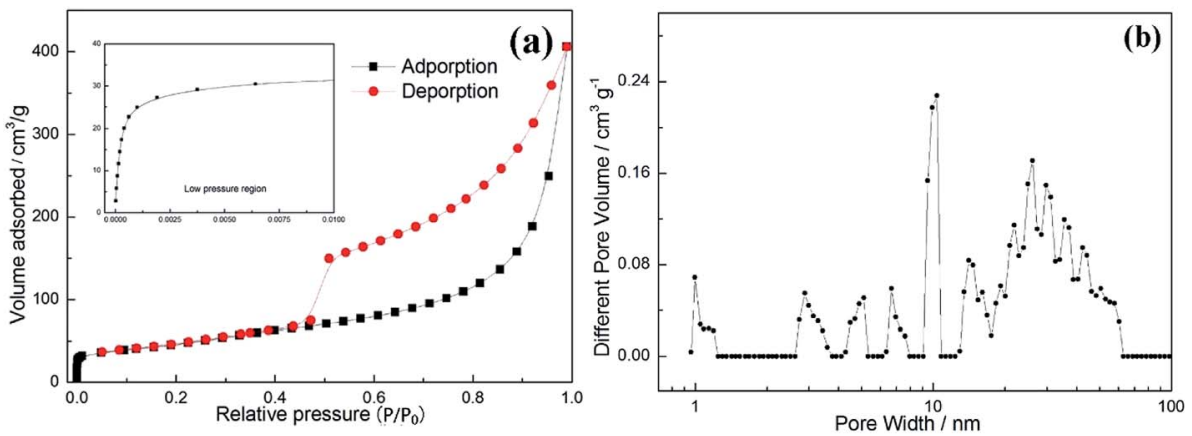

Fig. 6 (a) $\mathrm{N}_{2}$ adsorption-desorption isotherms of the CDC. (b) The curve of pore size distribution.

that three regions can be identified: (1) micropores $(0.7-2 \mathrm{~nm})$; (2) mesopores $(2-50 \mathrm{~nm})$; (3) macropores $(>50 \mathrm{~nm})$. These results are in consistent with the results from SEM and TEM. The specific surface area was computed based on BET equation, and the value is $171 \mathrm{~m}^{2} \mathrm{~g}^{-1}$, which is relatively higher than that reported for porous carbon synthesized by other methods. ${ }^{43-46}$

\subsection{Characterization of cathode products}

Fig. 7 shows the XRD pattern and SEM image of the deposit collected from the cathode and electrolyte. The observed peaks in Fig. 7(a) were identified as manganese and iron. The SEM micrographs of ferromanganese is given in Fig. 7(b). It displays almost similar and uniform particles, which are compact and fine. Few agglomerates present were composed of some small particles, and the average particle size varies from 0.5 to $2 \mu \mathrm{m}$.

The weight of the anode loss and the obtained cathode products were weighed. It is found that the amount of cathode products is four times than the amount of manganese ions added initially, which implied that most of ferromanganese deposits were fed from HCMnFe. Since we supposed both manganese and iron are reduced in a divalent state, the anode and cathode current efficiency are considered to be at least $92 \%$ and $80 \%$ respectively, which are computed via combining Faraday's law and eqn (1)-(3). The lost cathode current efficiency may be attributed to the loss of the powdered product during the collection process which was mixed with molten salts. If we can change the process parameters in the process of electrolysis, and make sure the cathode products are electrodeposited in bulk, the loss of current efficiency caused by cathode products mixed with molten salts may be reduced greatly.

The carbon content of the cathode product was measured as $0.59 \mathrm{wt} \%$. Compared with the HCMnFe (about $6.38 \mathrm{wt} \%$ ), there is a great decrease in the carbon content in the produced ferromanganese. The carbon content of the product is low enough for the requirement of GB (Chinese standard) for low carbon ferromanganese.

$$
w_{1}=\frac{I \times t \times w_{\mathrm{eq}}}{96485}
$$

where $w_{1}$ is theoretical weight obtained on cathode. $I$ represents the current recorded during electrolysis, A. $t$ is the electrolysis time, s. $w_{\text {eq }}$ refers to the equivalent weight of ferromanganese, and it was calculated according to eqn (2).

$$
w_{\mathrm{eq}}=\left[\frac{1}{100}\left(\frac{X \times z_{\mathrm{Mn}}}{W_{\mathrm{Mn}}}+\frac{Y \times z_{\mathrm{Fe}}}{W_{\mathrm{Fe}}}\right)\right]^{-1}
$$

where $X$ is the weight percentage of Mn in cathode products, and $Y$ is the weight percentage of Fe in cathode products based on the result of XRF, wt $\% . z_{\mathrm{Mn}}$ and $z_{\mathrm{Fe}}$ are the exchanged electron number of $\mathrm{Mn}$ and Fe respectively. $W_{\mathrm{Mn}}$ and $W_{\mathrm{Fe}}$ are atomic weight of Mn and Fe.

$$
\eta=\frac{w_{2} \times 100}{w_{1}}
$$

where $w_{2}$ is the weight of cathode products or the lost weight of anode after electrolysis, $\mathrm{g}$.

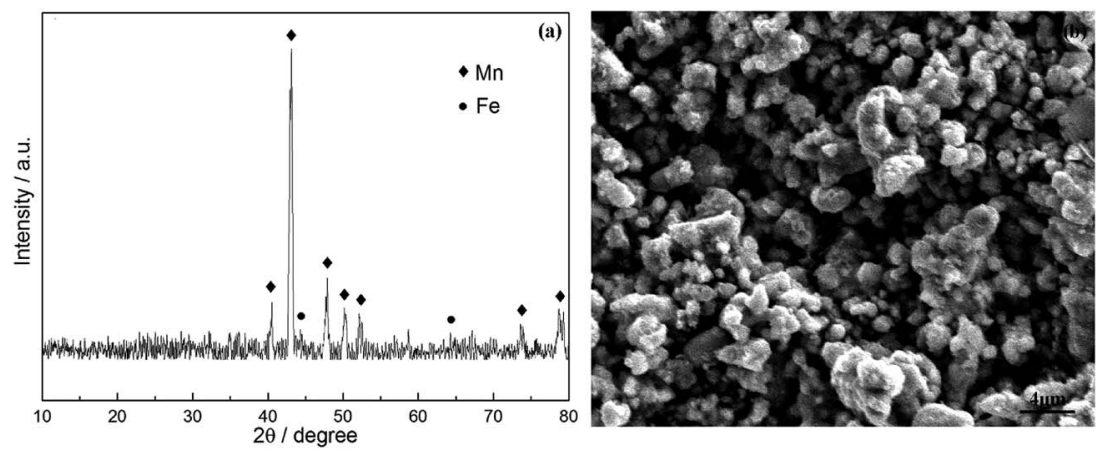

Fig. 7 (a) XRD pattern of deposited products on cathode and (b) SEM image of produced ferromanganese. 


\section{Conclusions}

It has been proved that carbide derived carbon (CDC) monoliths with a hierarchical pore structure and low carbon ferromanganese can be obtained at the same time via molten salt electrolysis in one electrolytic reactor. It is found that this hierarchical porous carbon with micropores, mesopores and macropores has a good graphite structure. Comparing to the traditional processes for the preparation of $\mathrm{CDC}$, there is no corrosive gas present in this method. In addition, the whole process consists of only two steps: the remelting procedure of HCMnFe and molten salt electrolysis. Therefore, it may provide a low-cost way to prepare hierarchical CDC because of the cheap raw material and simple process. The additional production of low carbon ferromanganese also contributes for its added value.

\section{Acknowledgements}

The authors are grateful for the financial support from National Natural Science Foundation of China, Project (51404001) and Anhui Province overseas scholars innovation project funding program.

\section{References}

1 F. Glenk, T. Knorr, M. Schirmer, S. Gütlein and B. J. M. Etzold, Chem. Eng. Technol., 2010, 33, 698-703.

2 A. Schlange, A. R. dos Santos, B. Hasse, B. J. M. Etzold, U. Kunz and T. Turek, J. Power Sources, 2012, 199, 22-28.

3 A. Silvestre-Albero, S. Rico-Frances, F. Rodriguez-Reinoso, A. M. Kern, M. Klumpp, B. J. M. Etzold and J. SilvestreAlbero, Carbon, 2013, 59, 221-228.

4 S. H. Yeon, S. Osswald, Y. Gogotsi, J. P. Singer, J. M. Simmons, J. E. Fischer, M. A. Lillo-Rodenas and A. Linares-Solanod, J. Power Sources, 2009, 191, 560-567.

5 C. H. Huang, Q. Zhang, T. C. Chou, C. M. Chen, D. S. Su and R. A. Doong, ChemSusChem, 2012, 5(3), 563-571.

6 S. G. Yu, K. Yubuta, T. Wada and H. Kato, Carbon, 2016, 96, 403-410.

7 A. R. Kamali and D. J. Fray, Carbon, 2014, 77(77), 835-845.

8 Q. Xu, C. Schwandt, G. Z. Chen and D. J. Fray, J. Electroanal. Chem., 2002, 530(1), 16-22.

9 D. Tang, H. Yin, X. Mao, W. Xiao and D. H. Wang, Electrochim. Acta, 2013, 114, 567-573.

10 C. Schwandt, A. T. Dimitrov and D. J. Fray, Carbon, 2012, 50(3), 1311-1315.

11 W. K. Hsu, J. P. Hare, M. Terrones and H. W. Kroto, Nature, 1995, 377(6551), 687.

12 W. K. Hsu, M. Terrones, J. P. Hare, H. Terrones, H. W. Kroto and D. R. M. Walton, Chem. Phys. Lett., 1996, 262(1), 161166.

13 W. K. Hsu, M. Terrones, H. Terrones, N. Grobert, A. I. Kirkland, J. P. Harea, K. Prassides, P. D. Townsend, H. W. Kroto and D. R. M. Walton, Chem. Phys. Lett., 1998, 284(3), 177-183.

14 S. Wang and G. Shao, J. Nanomater., 2016, 2016, 1-6.
15 L. Zhang, X. Qin, G. Shao, Z. Ma and S. Liu, Mater. Lett., 2014, 122(122), 78-81.

16 C. Wan, R. Zhang, S. Wang and X. Liu, J. Mater. Sci. Technol., 2016, DOI: 10.1016/j.jmst.2016.08.006.

17 M. McNallan, M. Mika and K. Y. Cheng, Synthesis of carbide derived carbon (CDC) by electrolysis of molten chloride salts, PRIME, Hawai'i Convention Center, 2016.

18 ASM Handbook, Alloy Phase Diagrams, ASM international, 1992, vol. 3, ch. 2, p. 9.

19 E. G. Castle, A. M. Mullis and R. F. Cochrane, Acta Mater., 2014, 77(4), 76-84.

20 W. Nickel, M. Oschatz, M. Lehr, M. Leistner, G. Hao, P. Adelhelm, P. Müller, B. M. Smarsly and S. Kaskel, J. Mater. Chem. A, 2014, 2(32), 12703-12707.

21 J. Chmiola, C. Largeot, P. L. Taberna, P. Simon and Y. Gogotsi, Science, 2010, 328(5977), 480-483.

22 S. H. Yeon, I. Knoke, Y. Gogotsi and J. E. Ficher, Microporous Mesoporous Mater., 2010, 131(1), 423-428.

23 P. Díaz-Arista, Z. I. Ortiz, H. Ruiz, R. Ortega, Y. Meas and G. Trejo, Surf. Coat. Technol., 2009, 203(9), 1167-1175.

24 K. Chen and G. D. Wilcox, J. Electrochem. Soc., 2008, 155(2), C53-C61.

25 W. Zhang and C. Y. Cheng, Hydrometallurgy, 2007, 89(3), 137-159.

26 M. J. Deng, P. Y. Chen and I. W. Sun, Electrochim. Acta, 2007, 53(4), 1931-1938.

27 J. A. M. Araujo, M. M. R. Castro and V. F. C. Lins, Hydrometallurgy, 2006, 84(3), 204-210.

28 J. Safarian and L. Kolbeinsen, INFACONXIII, Almaty, 2013, pp. 175-183.

29 G. Hils, A. Newirkowez, M. Kroker, U. Grethe, R. SchmidtJürgensen, J. Kroos and K. H. Spitzer, Steel Res. Int., 2015, 86, 411-421.

30 J. Gong, G. Wei, J. A. Barnard and G. Zangari, Metall. Mater. Trans. A, 2005, 36(10), 2705-2715.

31 D. Barbier, N. Gey, S. Allain, N. Bozzolo and M. Humbert, Mater. Sci. Eng., A, 2009, 500(1), 196-206.

32 J. Lu, D. Dreisinger and T. Glück, Hydrometallurgy, 2014, 141, 105-116.

33 M. Selecka and A. Šalak, Powder Metall. Prog., 2009, 9(2), 97. 34 S. Xiao, W. Liu and L. Gao, Ionics, 2016, 22(12), 2387-2390.

35 D. S. Kozak and L. R. Matricardi, Iron Steelmaker, 1981, 8(4), 28-31.

36 B. D. You, K. Y. Park, J. J. Pak and J. W. Han, Met. Mater. Int., 1999, 5(4), 395-399.

37 S. Xiao, W. Liu, L. Gao and J. Zhang, Arch. Metall. Mater., 2017, DOI: 10.1515/amm-2017-0233.

$38 \mathrm{M}$. Inagaki, New carbons - control of structure and functions, Elsevier, Amsterdam, 2000.

39 A. C. Ferrari and J. Robertson, Phys. Rev. B: Condens. Matter Mater. Phys., 2000, 61(20), 14095.

40 D. Puthusseri, V. Aravindan, S. Madhavi and S. Ogale, Energy Environ. Sci., 2014, 7(2), 728-735.

41 A. Chen, Y. Yu, H. Lv, Y. Wang, S. Shen, Y. Hu, B. Li, Y. Zhang and J. Zhang, J. Mater. Chem. A, 2012, 1(4), 1045-1047.

42 K. S. W. Sing, Pure Appl. Chem., 1985, 57(4), 603-619. 
43 I. Cameán and A. B. Garcia, J. Power Sources, 2011, 196(10), 4816.

44 G. Chen, W. Weng, D. Wu, C. Wu, J. Liu, P. Wang and X. Chen, Carbon, 2004, 42(4), 753-759.
45 J. Kim, J. Lee, Y. Choi and C. Jo, Carbon, 2014, 75(8), 95103.

46 X. Wang, C. Zuo, L. Jia, Q. Liu, X. Guo, X. Jing and J. Wang, J. Alloys Compd., 2017, 708, 134-140. 